\title{
Secondary syringomyelia
}

INSERM

\section{Source}

INSERM. (1999). Orphanet: an online rare disease and orphan drug data base. Secondary syringomyelia. ORPHA:99857

Secondary syring omyelia is a rare medullar disease defined as a development of a fluidfilled cavity or syrinx within the spinal cord due to blockage of CSF circulation (e.g., due to basal archnoiditis, mening eal carcinomatosis, various mass lesions), spinal cord injury (e.g., due to trauma, radiation necrosis, hemorrhage, spinal abscess), spinal dysraphism or intramedullary tumours. It presents with neuropathic pain, numbness, muscular weakness, changes in tone or spasticity or autonomic changes (hyperhidrosis, heart rate or blood pressure instability). Selective loss of pain and temperature with relative preservation of dorsal column function (touch and pressure) are classic findings. 